\title{
Tratamiento sobre política y economía en la prensa nacional tras el 15 octubre de 2017. Análisis de contenido
}

\section{Treatment about politics and economics in the national media after October $15^{\text {th }}$ of 2017 . Analisys of content}

\author{
Ángel Bracho*
}

\section{RESUMEN}

El propósito de este artículo es determinar la línea informativa de los medios de difusión masiva durante el mes de octubre de 2017, período posterior a las elecciones regionales en Venezuela. Los aportes teóricos corresponden a Cohen (1963), Rodríguez (2004), Wolf (1987), Martínez Albertos (1983), entre otros. La investigación se realizó en la Facultad de Comunicación Social de la Universidad Católica Cecilio Acosta, en Maracaibo, estado Zulia; fue de tipo descriptivo con diseño mixto (de campo y documental). La población estuvo conformada por 145 anuncios del diario Panorama, 254 noticias de "El Noticiero" de Televen y 143 publicaciones (tweets) de la cuenta @ElUniversal. Se realizó un monitoreo a los medios y una observación directa de las noticias; la medición se realizó con una ficha de recolección de datos y posteriormente fue tabulada a través de la estadística descriptiva. Entre los resultados destaca el predominio de la política como temática, con escasa, repetitiva y poco relevante información sobre otras fuentes. Se concluye que los medios se alinean con la polarización de la sociedad venezolana, marcando la pauta de la agenda pública y valiéndose sólo de la información con poca y/o nula realización de géneros de opinión e interpretativos.

Palabras clave: medios de difusión masiva, línea editorial, opinión pública; polarización, géneros periodísticos.

\footnotetext{
* Licenciado en Comunicación Social, mención Periodismo Audiovisual. Magister Scientiarium en Ciencias de la Comunicación, mención Sociosemiótica de la Comunicación y la Cultura. Docente de la Universidad del Zulia (LUZ), Universidad Dr. Rafael Belloso Chacín (URBE) y la Universidad Católica Cecilio Acosta (UNICA). Conductor del programa de Radio "Fuera de la Cancha" en LUZ RADIO 102.9 FM. Maracaibo, Venezuela. Correo electrónico: atbracho@urbe.edu.ve
} 
Tratamiento sobre política y economía en la prensa nacional tras el 15 octubre de 2017. Análisis de contenido

\begin{abstract}
The purpose of this article is to determine the information line of the mass media during the month of October 2017, after the regional elections in Venezuela. The theoretical contributions that served as support correspond to Cohen (1963), Rodríguez (2004), Wolf (1987), Martinez Albertos (1983), among others. The research was conducted at the Faculty of Social Communication of the Catholic University Cecilio Acosta, in Maracaibo, Zulia state; It was of a descriptive type with a mixed design (field and documentary). The population was conformed by 145 announcements of the newspaper Panorama, 254 news of "El Noticiero" of Televen and 143 publications (tweets) of the @ElUniversal account. Media monitoring and direct observation of the news was carried out; The measurement was made with a data collection form that was subsequently tabulated through descriptive statistics. Among the results, it stands out that politics predominates as a topic, with little, repetitive and little relevant information about other sources. It is concluded that the media align with the polarization of Venezuelan society, setting the tone of the public agenda and using only information with little and / or no realization of opinion and interpretative genres.
\end{abstract}

Key words: mass media, editorial line, public opinión, polarization, journalistic genres.

\title{
Introducción
}

La televisión y el periodismo impreso (con sus redes sociales incluidas) manejan una agenda informativa cuyas temáticas mantienen una repercusión sobre la opinión pública a la que se dirige. Esto adopta especial vigencia en Venezuela, un país absorbido y marcado por una fuerte polarización sociopolítica con discusiones orientadas a discernir sobre las acciones implementadas por los gobernantes y sus repercusiones en la cotidianidad ciudadana.

El 15 de octubre de 2017 se realizaron las elecciones regionales en Venezuela, evento en el que se eligieron los Gobernadores de los 23 estados del país para el ejercicio 2018 - 2022. El proceso estuvo contextualizado por la alta polarización y conflictividad sociopolítica en este país, manifestada por protestas en los estados y en las ciudades más importantes de la nación con un saldo de 142 muertos y 800 heridos (cifras de la Fiscalía General de la República), la convocatoria 


\section{Angel Bracho}

Telos Vol. 20, No. 3 (2018). 537-558

a una Asamblea Constituyente y una coyuntura económica caracterizada por una cada vez más acentuada escasez y altos precios de los rubros de primera necesidad; de igual forma se mantuvieron los bajos precios del petróleo (principal fuente de ingresos de la economía venezolana) y esfuerzos del gobierno nacional por mantener la inversión en sus planes sociales.

El entorno colocó a los medios de difusión masiva en la mira de la opinión pública respecto al análisis de la cobertura otorgada a los sucesos de año 2017, esto en un país en el que las líneas editoriales son catalogadas como "pro - gobierno" o "de oposición". Desde el sector oficialista, se acusó a los medios de promover las protestas de calle, mientras que, para la oposición, se incurrió en una autocensura para no comunicar la verdadera dimensión de las manifestaciones (conocidas como guarimbas) y evitar confrontaciones con el gobierno nacional. Vale recordar que la polarización sociopolítica en Venezuela tiene en el factor mediático a uno de sus principales estandartes sin tintas medias por la colectividad y con una credibilidad muy discutida por sus usuarios, quienes lo acusan de cambiar su rol mediador por uno más político partidista. Los controles cada vez más rigurosos del Estado en el flujo informativo y la mayor presencia de medios oficiales tradicionales han llevado a buena parte de las empresas comunicacionales privadas a adoptar un papel más ligero en su línea editorial y a desarrollar la plataforma multimedia como una vía alternativa de transmisión de la información sin el excesivo monitoreo oficial.

"El paisaje mediático de Venezuela no se entiende si no se analiza cómo el Estado ha pasado a configurarse como un Estado-Comunicador. Igualmente (...) las empresas familiares de medios se convirtieron en corporaciones multimedia. Estas se han profesionalizado y especializado para hacer de los medios toda una rama de las llamadas industrias culturales, que actúan en un mercado que no sólo es de orden económico, sino también simbólico." (Bisbal, 2014, en línea: https://ipysvenezuela.org/2014/06/12/medios-decomunicacion-social-en-venezuela-notas-sobre-el-nuevo-regimencomunicativo-por-marcelino-bisbal/)

Dada la trascendencia de los comicios regionales, el papel los medios de difusión masiva fue fundamental en la transmisión de campañas, acontecimientos e 
Tratamiento sobre política y economía en la prensa nacional tras el 15 octubre de 2017. Análisis de contenido

informaciones de carácter político y económico durante la campaña electoral, los comicios y en los días posteriores a ellos.

En este sentido, la presente investigación se propone determinar la línea informativa de los medios de difusión masiva durante el mes de octubre de 2017 en Venezuela. Para ello, indagará la mención sobre las noticias de las fuentes de política y economía en el informativo "El Noticiero" de la televisora Televen, el diario Panorama y la cuenta twitter @ElUniversal, posterior a la realización de las elecciones regionales, esto para estudiar cuáles fueron los lineamientos informativos principales tras los importantes comicios. Para tal fin, se analiza a): las temáticas predominantes en las informaciones publicadas por cada medio de comunicación seleccionado; b) cuáles informaciones resaltan en detrimento de otras posterior a la realización de las elecciones regionales; c) la inclinación política generalizada el abordaje de la información y d) los géneros periodísticos empleados en la estructuración del discurso periodístico, todo esto con base en el contexto informativo nacional.

\section{Metodología}

Para este estudio se toman como muestra 145 anuncios en 10 ediciones del diario Panorama, 254 noticias obtenidas en 20 emisiones del informativo "El Noticiero" de la televisora Televen (10 meridianas y 10 estelares) y 143 publicaciones (tweets) de la cuenta en twitter @ElUniversal; sobre este último caso, la muestra se seleccionó en dos franjas horarias: la primera de 11 am a 1 pm y el segundo de 4 pm a $7 \mathrm{pm}$. Se aplica un muestreo intencional fundamentado en la selección de los elementos con base en criterios o juicios realizados sobre los medios de comunicación y plataformas digitales presentes en Venezuela. En este sentido, los criterios de selección obedecen a la cobertura nacional de los medios seleccionados y en una distribución más equitativa de las noticias en su línea editorial. El trabajo presenta un diseño mixto (de campo y documental) de tipo Descriptivo de las diferentes 


\section{Angel Bracho}

Telos Vol. 20, No. 3 (2018). 537-558

situaciones y particularidades que contextualizan a la cobertura de las informaciones tras las elecciones regionales. La técnica de investigación es el monitoreo a los medios y la observación directa de las noticias reseñadas; la medición se realizó en función a una ficha de recolección de datos para posteriormente recibir la respectiva tabulación. La recolección de la muestra y su posterior análisis fue realizada en la ciudad de Maracaibo, estado Zulia desde el 16 al 31 de octubre del año 2017.

\section{Fundamentación teórica}

Desde el punto de vista teórico, el estudio se fundamenta en los planteamientos que analizan la intencionalidad de la producción de mensajes en los medios de comunicación y su repercusión en la opinión pública; en este sentido son aplicables los postulados de Wolf (1987) y Rodríguez (2004); en el aspecto relacionado a los géneros periodísticos se adaptan los enunciados de Fagor (1982), Martínez Albertos (1983) y García (2000).

\section{Los medios y la política}

Uno de los papeles más importantes de los medios de comunicación es informar y dar a conocer a los ciudadanos los partidos políticos mediante la cobertura mediática, difundiendo el mensaje de manera justa. Asimismo, el papel principal de estos medios en el entorno electoral es penetrar en la conciencia de cada individuo influenciándolos de esa manera para orientar su voto a determinada dirección, influyendo así de manera pública en la audiencia ya sea por propagandas políticas.

Dearing y Rogers (citado por Rodríguez, 2004: 17) establecen tres tipos de agendas complementarias en el proceso comunicativo. Estos criterios analizan el nivel de interés de las informaciones y su utilidad para los conformadores de la opinión pública. Así entonces existe una "agenda-setting de los medios", que mide los niveles de publicación de varios temas en los medios de comunicación; una "agenda-setting del público", la cual analiza la relevancia de las publicaciones en los receptores; por último, una "agenda-setting política", estudia las posturas e intencionalidades de los 
Tratamiento sobre política y economía en la prensa nacional tras el 15 octubre de 2017. Análisis de contenido

grupos políticos y las instituciones sociales respecto a los tópicos de índole social discutidos por los ciudadanos y los medios.

A efectos de esta investigación, se establece el estudio de acuerdo a los criterios de la "agenda-setting de los medios" por considerase como la más pertinente para este tipo de trabajo. Según la agenda de los medios, "El número de noticias que aparecen sobre un tema o asunto de estudio se mide en función de su importancia, páginas que ocupa, tiempo dedicado..." (Rodríguez, 2004: 18); existe entonces una relación casi simbiótica entre los contenidos aparecidos y las opiniones de los ciudadanos.

Donsbach (1995), establece algunos factores que favorecen la novedad y variedad en la emisión de una noticia: "la sorpresa, la tematización, la personalización y el negativismo". Así entonces, para analizar las agendas de los medios la técnica a ejecutar más recomendada es el análisis de contenido. Sobre esto, Rodríguez (2004) explica:

"El procedimiento consiste en realizar diferentes mediciones del tema objeto de estudio. Para ello, se contabiliza el número de artículos publicados, el número de páginas o columnas que ocupan, la ubicación que tienen dentro del medio o el total de minutos que le han sido dedicados en un periodo de tiempo, si se trata de un medio no escrito. El tiempo de duración del estudio no siempre es el mismo. Dependerá de los propios objetivos de la investigación para conocer el modo en que la opinión pública se ve influenciada por los medios durante un periodo corto o largo de tiempo" (Rodríguez, 2004: 18)

De acuerdo a este criterio, cumplir con la medición de la agenda de los medios implica seleccionar un tema y hacer un seguimiento de su cobertura durante el tiempo considerado pertinente y adecuado por el investigador.

\section{Sobre la Producción, distribución y consumo de mensajes en los medios Teoría de la Agenda Setting}

Esta teoría analiza la forma en la que los medios transmiten a las audiencias los temas protagonistas de su agenda de discusiones diarias como parte de la opinión pública. "los medios de comunicación cuentan en su haber o seleccionan de alguna 


\section{Angel Bracho}

Telos Vol. 20, No. 3 (2018). 537-558

manera el índice de temas resaltados, temas o índices que serán traspasados por la agenda de los medios a la agenda del público" (Rodríguez 2004:15). En este sentido, el medio no decide sobre qué tópicos debe analizar u opinar su audiencia, mas sí le coloca sobre el tapete los hechos, sucesos, o dinámicas sociales sobre las cuales tiene pensar. "La prensa no tiene mucho éxito en decir a la gente qué tiene que pensar, pero sí lo tiene en decir a sus lectores sobre qué tienen que pensar" (Cohen, 1963: 13). A través de la agenda setting se determina las noticias con mayor interés informativo y cuánta relevancia se les da en el medio periodístico.

La agenda setting influye en la transferencia de información al individuo debido a factores como la inquietud, el desconocimiento del mismo y su necesidad por mantenerse informado. La idea principal de esta teoría, se centra en percibir que las representaciones destacadas en los medios también sean destacadas por los receptores.

\section{El Gatekeeper}

El gatekeeper o portero es un agente, representado por un individuo o un grupo que decide qué información deja pasar o no a través de un filtro. La teoría del Gatekeeper o guardabarreras plantea el modo de selección de los editores de las distintas secciones de un medio informativo, y el rechazo de otras consideradas menos importantes.

"Las decisiones del gatekeeper no son realizadas sobre la base de una valoración individual de noticiabilidad, sino más bien en relación a un conjunto de valores, que incluyen criterios profesionales y organizativos, como la eficiencia, la producción de noticias, la velocidad." (Robinson, 1981: 97)

Wolf (1987), señala que los análisis de los actos comunicacionales informativos se pueden cumplir estudiando a los medios de difusión masivos como ente emisor y el potencial efecto de los mensajes emitidos en los receptores. En este sentido, el papel de los medios como emisores de las noticias integra un 
Tratamiento sobre política y economía en la prensa nacional tras el 15 octubre de 2017. Análisis de contenido

doble criterio complementario: el sociológico, que considera factores como sus características sociológicas, culturales, de los procesos sociales de los ciudadanos, etc.; por otra parte, refiere a una base organizativa, en la centrada en "la lógica de los procesos" de producción en la comunicación de masas y el tipo de organización de trabajo en la 'construcción' de los mensajes" (Wolf 1987: 203 204)

\section{El Newsmaking}

En el Newsmaking (construcción de la noticia) se puede definir como la teoría de la noticiabilidad de un suceso. Es decir, se encarga de recoger entre numerosos acontecimientos una cantidad limitada de noticias para colocarla en la agenda de conversación de la opinión pública. Se fundamenta en cómo los criterios de noticiabilidad implican una "distorsión involuntaria", debido a que la maquinaria productora de noticias parte del supuesto (completamente intencionado) de los presuntos intereses de las audiencias. Bajo este criterio, el periodista pasa a ser un simple transmisor de la información, con dificultades para sobrellevar todas las variables que permiten diferenciar el tratamiento concedido a una información y a una noticia. Martini (2000) así lo resume:

"Las noticias serían el producto de la selección y el control de las formas de procesamiento que responden a "instrucciones" (más o menos explicitadas) de la empresa y a actitudes y valores consensuados o al menos aceptados (la distorsión consiente) y de la articulación de prejuicios, valores compartidos con el medio y la sociedad, representaciones del propio trabajo y que están implícitos (la distorsión inconsciente o involuntaria). " (Martini, 2000, pág. 77)

En este sentido, Golding-Elliot (1979), consideran a los valores como los criterios que determinan cuáles acontecimientos merecen ser convertidos en noticia y cuáles no; con ellos, los editores de prensa pueden decidir entre el material disponible en la redacción los elementos dignos de ser incluidos en el producto final. De igual modo, "funcionan como líneas-guía para la presentación del material, sugiriendo qué 
Angel Bracho

Telos Vol. 20, No. 3 (2018). 537-558

elementos se pueden enfatizar u omitir y dónde dar prioridad en la preparación de las noticias presentadas al público". (Golding-Elliot. 1979: 114).

Wolf (1987), establece unas características sustantivas por las cuales una información se convierte en noticia. Estas características se refieren a la importancia y significación que un evento genera en los receptores, es decir, atañen a quienes leen, escuchan o ven una noticia, y para despertar la atención de las masas, deben conjugarse 4 criterios determinantes: a)Grado y nivel jerárquico de los sujetos implicados en el acontecimiento noticiable (si se relaciona con una personalidad importante, el acontecimiento tiene más posibilidades de ser noticia); b) Impacto sobre la nación y sobre el interés nacional (qué tan "significativo" es un hecho en un contexto cultural e intereses de un país; c) Cantidad de personas implicadas en el acontecimiento(mientras más personas estén inmersas en el hecho, la noticia tendrá más importancia) y d) Importancia y significatividad del acontecimiento respecto a la evolución futura de una determinada situación, se analiza un suceso por la relevancia para el público en función a lo insólito, lo curioso y lo cotidiano.

Si los valores gobiernan las creencias sociales y monitorean las dimensiones evaluativas y las actitudes, entonces, desempeñan un papel central en la construcción de la ideología de los grupos humanos. Las ideologías proporcionan la base de juicios que le indica a una sociedad qué está bien o mal, qué es correcto o incorrecto y facilitan guías básicas para la percepción social y la interacción (Van Dijk, 2008).

Todos los planteamientos esbozados hasta ahora, permiten explicar y analizar las razones por las cuales algunas informaciones son resaltadas en detrimento de otras en las fuentes de la política y economía en la muestra seleccionada. Su comprensión es significativa para el análisis del presente trabajo.

\section{Los géneros periodísticos}

De acuerdo a Martínez (1983), los géneros son "las diferentes modalidades dela creación literaria destinadas a ser divulgadas a través de cualquier medio de 
Tratamiento sobre política y economía en la prensa nacional tras el 15 octubre de 2017. Análisis de contenido

difusión colectiva" (Martínez, 1983: 272). Bajo este criterio, los géneros representan una forma de textos o manifestaciones comunicativas facilitadores de la divulgación de un mensaje acorde a las necesidades expresivas del periodista y su receptor.

Esta investigación adopta la tradicional distinción de los géneros periodísticos, en informativos, interpretativos y de opinión. Estas modalidades se observan con mayor frecuencia en los contenidos informativos de los medios de comunicación.

- Los géneros informativos es decir: a) la noticia, entendida como la unidad mínima de contenido de la información; incluye los sujetos, la acción y las circunstancias de lugar y tiempo; b) la encuesta "es un género perteneciente al periodismo informativo que tiene como objetivo reflejar la opinión de un grupo de personas" (Dragnic, 1994:91) sobre un tema del que no tienen por qué ser expertas; una encuesta funciona para el estudio de actitudes y pensamientos de la población sobre un tema determinado y además aplica a todo tipo de información; c)la entrevista entendida como "un diálogo con una persona que es fuente de información y, por consiguiente, tiene algo que decir que el público tiene derecho a saber e interés en conocer". Puede ser noticiosa, de opinión, o de personalidad. (García, 2000: 88).

- Los géneros de opinión: en ellos, el autor califica los hechos y a sus protagonistas con intenciones de juicios valorativos. Entre estos géneros están: a) la Crítica: es la reseña valorativa de una obra literaria, artística o espectacular, expuesta a la consideración y disfrute del público. Incluye una evaluación del autor sobre lo que está describiendo; b) el comentario: permite aportar la interpretación de un experto o especialista en el tema. Hay dos modalidades: la del comentarista permanente y la del esporádico. La del permanente, externo o interno a la redacción da continuidad a sus análisis y genera una familiarización mayor con la audiencia; c) el artículo: entendido como "el juicio, análisis, opinión o comentario que se realiza a través de un escrito firmado por un autor, en el que se da sus puntos de vista o ideas, en torno a un hecho que puede ser o no de actualidad" (Wagner, 2000: 310); d) la columna, es decir, uno de los géneros más apropiados para analizar, interpretar u opinar sobre un hecho 


\section{Angel Bracho}

Telos Vol. 20, No. 3 (2018). 537-558

determinado; e) el editorial, empleado por el medio de comunicación para manifestar su postura oficial sobre un hecho de interés general; por último, f) la crónica comprendida como el relato cronológico sobre un acontecimiento desde su principio hasta su final, para resaltar sus detalles más importantes con breves y muy puntuales apreciaciones personales del redactor.

- Los géneros interpretativos clasificados en: a) la crónica considerada como un subgénero mixto porque combina el relato de los hechos con el análisis y valoración de sus posibles causas para predecir las posibles repercusiones. La crónica "tiene como fin el análisis y la valoración, es decir, se hace en ella un uso frecuente de datos explicativos y estimativos (...) El análisis sirve para situar a éstos (los hechos) en un determinado contexto que sirve al receptor para evaluar consecuencias" (Fagor, 1982: 104); b) El reportaje presenta un hecho real, acaecido recientemente. Es la modalidad periodística interpretativa por excelencia. El presente es su tiempo de enunciación y está asociado a la actualidad. Fundamentalmente concreta el análisis y la descripción de la acción informativa (García, 2000). Parte de un hecho con sus antecedentes, comparaciones, derivaciones y consecuencias.

\section{Resultados y análisis}

En este apartado se procede a desglosar el análisis realizado a 145 textos del diario Panorama, 254 noticias del informativo "El Noticiero" de la televisora Televen y 143 publicaciones (tweets) de la cuenta en twitter @ElUniversal, para totalizar así 542 noticias estudiadas durante el 16 al 30 de octubre de 2017. Los gráficos son realizados en función a tres ítems: estructura temática, inclinación política y géneros periodísticos en una medida comparativa entre todos los medios seleccionados. 
Tratamiento sobre política y economía en la prensa nacional tras el 15 octubre de 2017. Análisis de contenido

Ítem No. 1 Estructura Temática.

\section{Gráfico No. 1 "El Noticiero"}

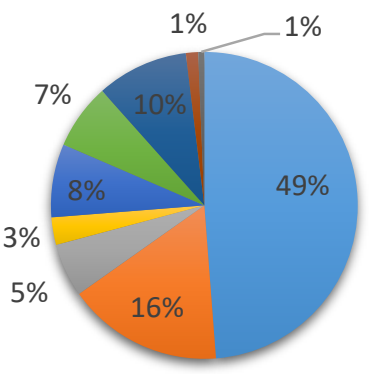
Política y Economia
Sucesos
Salud
- Tecnologia
- Comunidad
Deportes
- Farandula
- Servicios
atros

Fuente: Elaboración propia

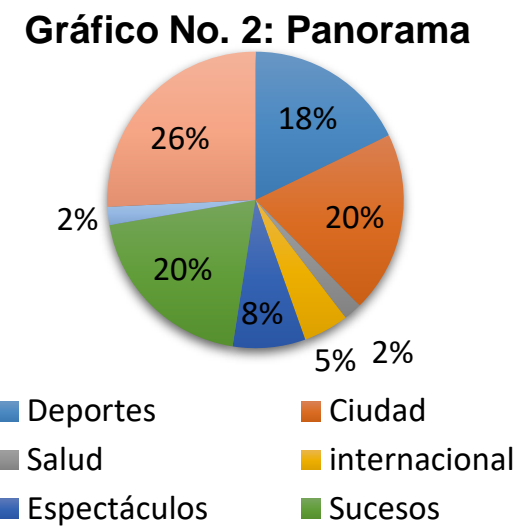

Fuente: Elaboración propia 


\section{Gráfico No. 3 @EIUniversal}

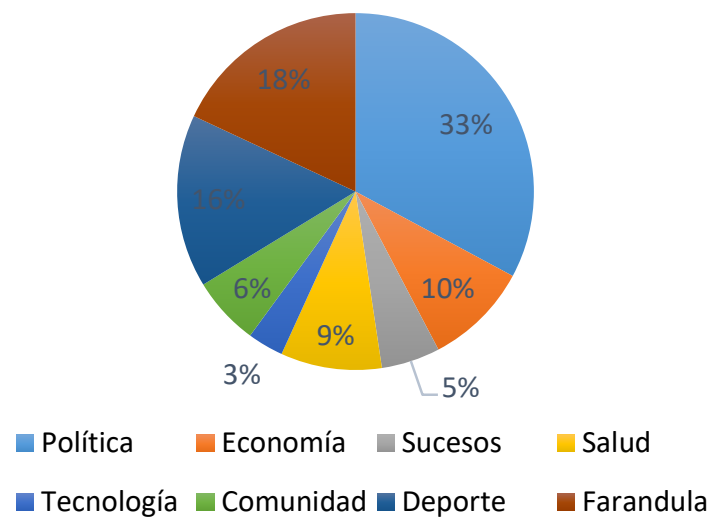

Fuente: Elaboración propia

En "El Noticiero" (Gráfico No. 1) la temática predominante es de política con 49\% (237 noticias), seguida de economía con 16\%, (66 noticias), farándula 14\% (60), comunidad con 48, deportes mostró 43 notas, mientras salud 35 y tecnología sólo marcó un 3\% con 18 noticias. Las noticias de política estaban relacionadas con las elecciones regionales del 15 de octubre, partiendo de los resultados, posturas internaciones y declaraciones de dirigentes políticos, ministros del país y la ciudadanía. Varias de las informaciones abarcaban entre dos y tres temáticas simultáneamente, particularmente entre económica y política o sucesos y economía.

En Panorama (Gráfico No. 2), 130 informaciones (26\%) pertenecen a la fuente de política, el contenido informativo predominante se refirió al rechazo de Juan Pablo Guanipa al ser convocado por la Asamblea Nacional Constituyente para realizar su juramentación ante dicha instancia. La fuente sucesos abarca 103 noticias (20\%), 94 deportes (18\%), 100 ciudad (20\%). De igual forma, 34 informaciones (7\%) están 
Tratamiento sobre política y economía en la prensa nacional tras el 15 octubre de 2017. Análisis de contenido

relacionadas con el arte y espectáculos, mientras el resto de la temática se distribuye, $5 \%$ (23 noticias) mundo y 8 noticias en salud, (2\%). El diario Panorama, le dio mayor cobertura a las noticias de ciudad y política en la semana del 16 al 23 de octubre, realizando incluso, un especial titulado "Regionales" en donde agrupaban los acontecimientos, opiniones, sucesos, perfiles e informaciones relacionadas al proceso electoral. Durante la semana de 24 al 30 de octubre destacó la cobertura del diálogo entre el gobierno nacional y la oposición en República Dominicana, las declaraciones del vicepresidente ejecutivo Tareck El Aissami sobre la postura de la oposición ante las elecciones municipales. En un segundo plano destacaron los temas sobre economía, tales como el aumento de la carne anunciado por la Federación Nacional de Ganaderos.

En @ElUniversal, el 33\%, equivalente a 111 noticias, refieren a temas de política publicadas; estas noticias fueron publicadas con mayor auge los días posteriores a las elecciones de gobernadores en el país, destacándose la lista de los candidatos electos y reacciones de los partidos políticos. El 18\% representa las 61 publicaciones de farándula, seguido por el $16 \%$ de deporte con 52 informaciones. Estas publicaciones hacían referencia a artistas y deportistas del exterior, pocas fueron las publicaciones resaltando el talento nacional. Por su parte, el 10\% iba de la mano de economía con 32 informaciones, en ella destacaban precios del OPEP y el precio del aumento de la carne. El 9\% pertenece a salud con 31 publicaciones. Destacándose publicaciones como: cuida tu piel y cómo prevenir la caspa. Menor cobertura recibieron las fuentes de comunidad (6\%), sucesos (5\%) y tecnología (3\%).

Ítem No. 2 Inclinación política. 
Angel Bracho

Telos Vol. 20, No. 3 (2018). 537-558

\section{Gráfica No. 4 "El Noticiero"}

Fuente: Elaboración propia

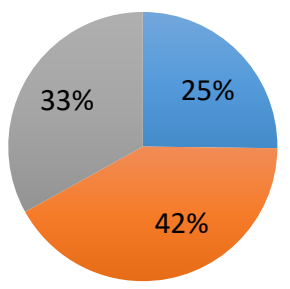

A favor En contra Neutral

\section{Gráfico No. 5 Panorama}

$23 \%$

$40 \%$

$37 \%$

A favor En contra Neutral

Fuente: Elaboración propia

Gráfico No.6 @EIUniversal

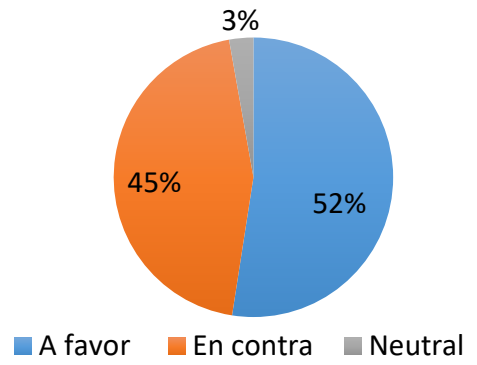

Fuente: Elaboración propia 
Tratamiento sobre política y economía en la prensa nacional tras el 15 octubre de 2017. Análisis de contenido

"El Noticiero" de Televen mostró la mayor parte de las noticias tanto de economía como de política con una inclinación política contraria al gobierno nacional con 106 informaciones. En este sentido, destacó la mención reiterativa de la no juramentación de Juan Pablo Guanipa como gobernador electo del estado Zulia ante la Asamblea Nacional Constituyente y las denuncias de actores políticos nacionales e internacionales sobre presuntas irregularidades en las elecciones regionales del 15 de octubre. En cuanto a las informaciones a favor del gobierno nacional (45\%), destaca el nombramiento de Francisco Arias Cárdenas como presidente de CORPOZULIA y los planes de reestructuración de las políticas por parte de los nuevos gobernadores oficialistas. Hay casos de informaciones sobre otras fuentes a las que se les concede una orientación política o económica; por ejemplo, temas como la lucha contra el cáncer de mama o casos de difteria, con alusiones a entes como el Ministerio de Salud y la carencia de investigaciones o estadísticas relacionadas a estas dos problemáticas de salud.

"El Noticiero" mostró predominantemente una inclinación política en contra del gobierno. El $42 \%$ de las informaciones transmitidas son en contra del Gobierno Nacional mientras que las que se publican a favor sólo tienen un $28 \%$. La mayoría de las noticias pro-gobierno son transmitidas entre el primer y el segundo segmento también mostrando una prioridad a las noticias pro gobierno para camuflar el alto número de noticias de oposición.

En contraste, Panorama muestra un $40 \%$ a favor del gobierno nacional, destacando el seguimiento a las reacciones posteriores a las elecciones regionales realizadas el 15 de octubre en la que los candidatos pro - gobierno, obtuvieron la mayoría de las gobernaciones; resaltó además las promesas de gestión de los nuevos mandatarios, cubriendo incluso toda una página para mostrar sus trabajos realizados, como fue el caso del gobernador electo del estado Miranda, Héctor Rodríguez con una inclinación visible a favor del Gobierno. 
El 37\% "en contra" publica las opiniones y declaraciones emitidas por los cuatro gobernadores electos de oposición, en las que mencionaban su desacuerdo con la juramentación ante la Asamblea Nacional Constituyente. Tal fue el caso de la gobernadora del estado Táchira Laidy Gómez, quien además obtuvo varios espacios en las informaciones de los días 17,18 y 19 de octubre por su negativa y posterior juramentación en la ANC.El 23\% restante equivale a 33 informaciones "neutrales", resaltando hechos como la falta de divisas en el país, el aumento de la carne anunciado por el presidente de Fedenaga y las impresiones por el aumento del transporte público en Maracaibo.

Similar orientación ocurre en @ElUniversal medio con 52\% de sus tweets mostrando una ligera tendencia a favor del gobierno nacional. Destaca, la reiterada mención de las acciones de los gobernadores electos del oficialismo en las elecciones regionales y su juramentación ante la Asamblea Nacional Constituyente (ANC).Por su parte el $45 \%$ hace alusión a la destitución del gobernador electo por el estado Zulia, Juan Pablo Guanipa, tras su no juramentación ante la ANC, además de no reconocer los resultados emitidos por el Consejo Nacional Electoral (CNE). El 3\% restante, se emplea para mencionar temas como el incremento de la carne de res anunciando por la Federación de Ganaderos de Venezuela.

Ítem No. 4 Géneros Periodísticos

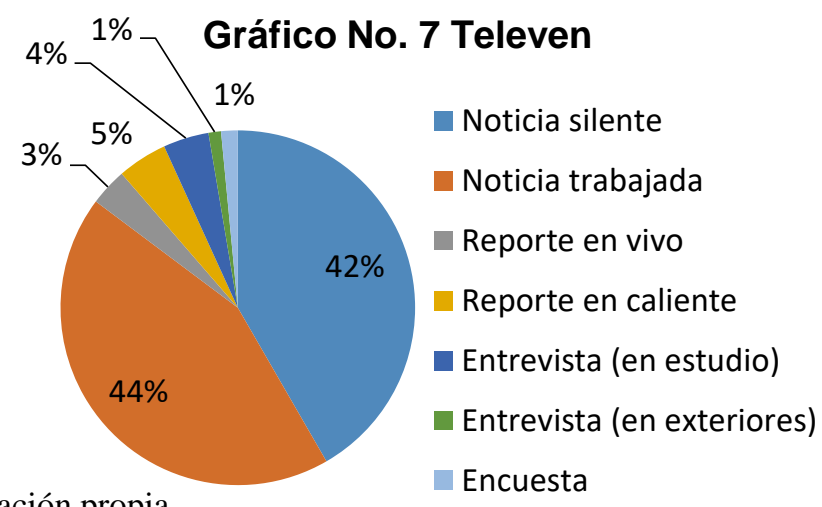

Fuente: Elaboración propia 
Tratamiento sobre política y economía en la prensa nacional tras el 15 octubre de 2017. Análisis de contenido

\section{Gráfico No.8 Panorama}

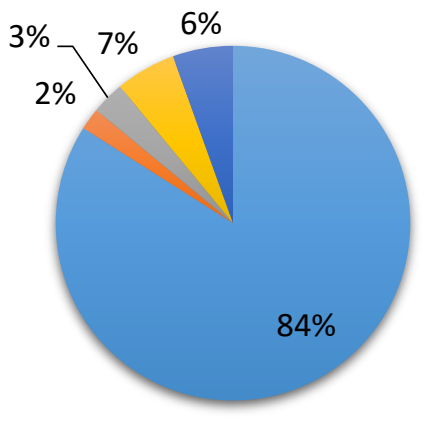

Noticia

Reseña

Entrevista

Artículo

Columna

Fuente: Elaboración propia

\section{Gráfico No.9 @ElUniversal}

Fuente: Elaboración propia

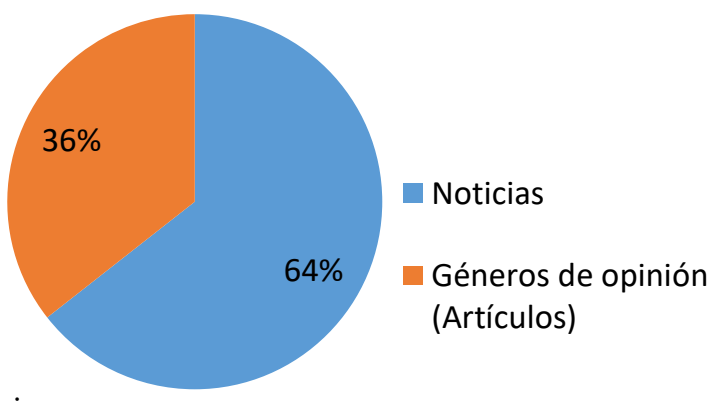

En "El Noticiero" emplea en mayor grado los géneros periodísticos informativos, con predominio de las noticias silentes (40\%) principalmente en las emisiones meridianas y noticias trabajadas (40\%) durante las emisiones estelares. Este informativo hace poco uso de géneros como la entrevista o encuestas, con sólo un 17\%. Resaltan también, los "reportes en caliente" y las transmisiones en vivo (20\%).

En Panorama, el 89\% de los textos (129 informaciones) pertenecen al género informativo, predominando el uso de noticias y reseñas (122 y 3 respectivamente). 


\section{Angel Bracho}

Telos Vol. 20, No. 3 (2018). 537-558

Las informaciones mencionan temas como el rechazo de los usuarios al aumento del pasaje del transporte público, la juramentación ante la ANC de gobernadores afectos al gobierno y la exhortación a los opositores a cumplirla de igual forma; también se trata el aumento del precio de la carne de res anunciada por FEDENAGA. El 11\% restante, pertenece al género de opinión con la publicación de artículos tales como "Elecciones y viraje económico" de Leopoldo Puchi, "'Regionales, emoción y racionalidad” de Maryclen Stelling y “¿Qué pasó?” de Luis Vicente León.

La cuenta@ElUniversal también presenta mayormente noticias. El 64\% de los mensajes, equivalentes a 143 noticias son publicadas en las fuentes de política, economía, deportes, farándula, entre otros, y un 36\% (79 textos) se destinan a artículos de opinión. Destacan los textos "Gracias Zulia" por Francisco Javier Arias Cárdenas y "Venezuela en caos” por Juan Pablo Guanipa.

\section{Conclusiones}

Los medios venezolanos mantienen una alta presencia de informaciones de carácter político, con una discreta, pero clara línea editorial.

La política se mantiene como la temática predominante, otorgándose mayor cobertura a las reacciones tras las elecciones regionales de octubre, con la tradicional polarización entre los candidatos ganadores de y perdedores del sector gobierno y oposición. La jerarquización de los contenidos informativos y las líneas editoriales es muy clara, puesto que se otorga más importancia a las noticias de política en comparación a las de otro renglón. Viniendo de medios de difusión masiva con cobertura nacional, la distribución de su línea editorial debería ser más equitativa para así poder tener ciudadanos actualizados e informados, pero esto no es así. La carga ideológica de los medios analizados coloca con preeminencia las noticias sobre política, situación reflejada diariamente en el diálogo del venezolano.

Resulta llamativa la escasa, repetitiva y en ocasiones poco relevante información sobre los temas más comentados por la sociedad venezolana en día a día. Los tópicos de "salud" "tecnología" "sucesos" y especialmente "comunidad" tuvieron 
Tratamiento sobre política y economía en la prensa nacional tras el 15 octubre de 2017. Análisis de contenido

bajos porcentajes de cobertura, lo que evidencia una frecuencia muy mínima comparada con política. No se considera importante lo social, aquello presente en el día a día de las ciudades o en sus calles. Así, los elementos contextuales determinan la agenda informativa en los medios de comunicación. Al tratarse de una sociedad con altos niveles de polarización político - social, esta tendencia muestra una vez más el impacto que los mensajes emitidos por los medios tienen en la formación de una corriente de opinión pública, al conseguir un "eco" casi instantáneo y muy efectivo en la ciudadanía.

Las noticias de economía reciben baja cobertura y las que reciben mayor insistencia son politizadas por las declaraciones de alguna persona afecta al gobierno o viceversa, sin realizar un tratamiento informativo para el ciudadano común. Esto contribuye a desinformación de la población en temas tan presentes como la implementación de la criptomoneda, el sistema cambiario de divisasy su fluctuación producto del impacto en la sociedad del denominado "mercado paralelo", el precio del barril del petróleo, la escasez de medicinas y alimentos, el desabastecimiento, el bachaqueo y otros temas que afectan al venezolano.

En cuanto a la inclinación política pudo determinarse tendencias opuestas entre los medios analizados. Existe un contraste entre Panorama y @Eluniversal, los cuales muestran una línea editorial a favor del gobierno nacional, a diferencia de " $E l$ Noticiero", que evidencia un predominio de informaciones de oposición al gobierno nacional, escondida en una "neutralidad" poco percibida. Los altos porcentajes de "imparcialidad" registrados dejan ver una dinámica no tan ceñida a reseñar informaciones para captar la atención de los usuarios, es decir, los medios publican informaciones no ligadas al interés del ciudadano venezolano. Bajo esta premisa los medios no escapan de la polarización que engloba a la sociedad venezolana.

La "politización" de las informaciones no viene acompañada de una cobertura adecuada de las noticias. Por ejemplo, Panorama, en plena efervescencia de los resultados electorales del 15 de octubre, realizó poca mención de las propuestas y 
planes de gobierno de los candidatos electos; en este sentido, menos mención se hace respecto a las acciones para abordar el tema económico regional y nacional. El periódico muestra una inclinación muy marcada hacia lo político, lo cual genera dudas sobre la intención de informar con profundidad los problemas del país.

Predominan los géneros periodísticos informativos, resaltando en el caso de "El Noticiero" el mayor uso de noticias trabajadas y silentes. Este tipo de discurso se emplea principalmente para las noticias correspondientes de la fuente política y en la mayoría de los casos suelen estar en los dos primeros segmentos del noticiero; igual situación ocurre con Panorama y @ElUniversal, cuyos textos publicados corresponden a noticias, reseñas y entrevistas; hay poco empleo de géneros de opinión (artículos y columnas) y nula realización de reportajes. Esto refleja la poca investigación de los medios de comunicación analizados, algo muy presente en una rutina periodística que obvia la matriz de opinión y enfocada sólo en la información.

\section{Referencias bibliográficas}

Bisbal, Marcelino. (2014). Medios de Comunicación Social en Venezuela. Notas sobre el nuevo régimen comunicativo. Instituto Prensa y Sociedad Venezuela. En Línea: https://ipysvenezuela.org/2014/06/12/medios-decomunicacion-social-en-venezuela-notas-sobre-el-nuevo-regimencomunicativo-por-marcelino-bisbal/ consulta: 08/08/2018

Cohen, Bernard. (1963). The press and foreign policy. Princeton University Press. USA.

Donsbach, Wolfang. (1995). Contenidos, utilización y efectos de la comunicación política. En Muñoz Alonso, A. y Rospir, J.A., Comunicación política. España.

Dragnic, Olga. (1994). Diccionario de comunicación social. Editorial Panapo. Venezuela.

El Universal. (2017). Noticias extraídas del 16/10 al 31/10/2017. Extraído de: https://www.eluniversal.com consulta: 31/10/2017.

Fagor, Carlos. (1982). Periodismo interpretativo. El análisis de la noticia. Editorial Mire. España,

García, J. Jesús. (2000). Información Audiovisual, Tomo II: Los géneros. Editorial Paraninfo. España. 
Tratamiento sobre política y economía en la prensa nacional tras el 15 octubre de 2017. Análisis de contenido

Golding, Peter, Philip, Elliot. (1979). News Values and News Production. Media Studies: A Reader. Eds. Paul Marris and Susan Thornham. New York University Press. USA.

Martínez A., José Luis. (1983). Curso General de Redacción Periodística. Mitre. España.

Martini, Stella. (2000) Periodismo, noticia y noticiabilidad. Enciclopedia latinoamericana de sociocultura y comunicación. Grupo Editorial Norma. Colombia.

Panorama. (2017). Noticias extraídas del 16/10 al 31/10/2017. Extraído de: https://www.panorama.com.ve. Consulta: 31/10/2017.

Robinson, Gertrude. (1981). News Agencies and World News. University Press. Germany.

Rodríguez D., Raquel. (2004). Teoría de la Agenda Setting, aplicación a la enseñanza universitaria. Observatorio Europeo de Tendencias Sociales. España.

Televen. (2017). Noticias extraídas del 16/10 al 31/10/2017. Extraído de: https://www.televen.com/elnoticiero. Consulta: 31/10/2017.

VAN DIJK, Teun A. (2008). Semántica del Discurso e Ideología (Traducción de Cristina Perales). Revista Discurso \& Sociedad, Issn 1887-4606, Vol. 2, No. 1, Págs. 201-261. En línea: http://www.dissoc.org/ediciones/v02n01/DS2\%281\%29Van\%20Dijk.pdf consulta: 20/07/2010.

Wagner, Carlos. (2000). Déjame que te cuente: los géneros periodísticos y su ética profesional. Editorial Trillas. México.

Wolf, Mauro (1987). La Investigación de la comunicación de masas. La Teoría Crítica. Paidós. España. 